\title{
Development of Capsules for Administering Drugs or Collecting Specimens in the Intestine
}

\author{
Kazuhiko Yagata, ${ }^{1 *}$ Yukio Sekigughr, ${ }^{2}$ \\ Takahisa Hosokawa, ${ }^{3}$ Masaru Shibata, ${ }^{4}$ \\ Yasuo Noguchi ${ }^{1}$ and Tomotari MitsuoKa ${ }^{5}$ \\ 1S. B. Medical Co., Ltd., 495 Akiba-cho, Totsuka-ku, Yokohama, 245 Japan, ${ }^{2}$ Department of \\ Rehabilitation Engineering, The Institute of Vocational Training, Sagamihara, Kanagawa, \\ 229 Japan, ${ }^{3}$ Koken Co., Ltd., Shinjuku-ku, Tokyo, 161 Japan, ${ }^{4}$ Sumitomo Bakelite \\ Co., Ltd., Minato-ku, Tokyo, 108 Japan, and ${ }^{5}$ Department of Biomedical \\ Science, Faculty of Agriculture, The University of Tokyo, Bunkyo-ku, \\ Tokyo, 113 Japan
}

(Received 30 March, 1987)

\begin{abstract}
Sampling capsules were developed. At the desired site in a digestive tract, the contents can be collected by the capsules. A resonance circuit composed of the Ni-Ti coil and tip condenser was installed in a capsule, and the capsule was operated by high frequency wave irradiation, $2.7 \mathrm{MHz}$, from outside of the body. The capsule could be successfully operated in water irradiated $6 \mathrm{~cm}$ apart from the capsule. By the aid of the specific suction valves, a sample of more than $100 \mu \mathrm{l}$ can be collected, and the valve is helpful to prevent backflow. For practical purposes, the price and size of the high frequency induction heating apparatus should be examined further.
\end{abstract}

Key words: Capsule; intestinal contents collection; Ni-Ti SMA; high-frequency irradiation; resonance

Investigation of intestinal microbial ecology by examining the intestinal microflora, examination of the digestive functions and diagnosis of various digestive diseases, administration of drugs to a specified site of the intestine, and exploration of the drug metabolism within a digestive tract may be accomplished by orally administrating a capsule. At the desired site in the digestive tracts, drugs may be administered, or the contents may be collected by the capsule, and then the capsule is recovered with feces (2-4).

The conventionally used capsules for such purposes are operated by a battery, and there are problems in price and safety of the capsule.

In the present paper, a shape-memory alloy (Ni-Ti SMA) is used as the actuator, and the alloy is operated by heating with high frequency wave energy. Various experiments have been done, and the possibility of actual use is explored.

\section{Materials and Methods}

\section{1) Structure of the sampling capsule}

The capsule is made of the following parts.

(1) Outer part of the capsule: Made of polycarbonate with cylindrical shape.

(2) Inner part of the capsule: A piston made of Teflon ${ }^{\circledR}$.

(3) Suction valve: A check valve with 2 leaves of silicon rubber, set near the sampling port.

(4) Exhaust valve: Air is expelled from the capsule when specimens are collected.

(5) Resonance circuit: A closed circuit composed of a coil made of $\mathrm{Ni}-\mathrm{Ti}$ 

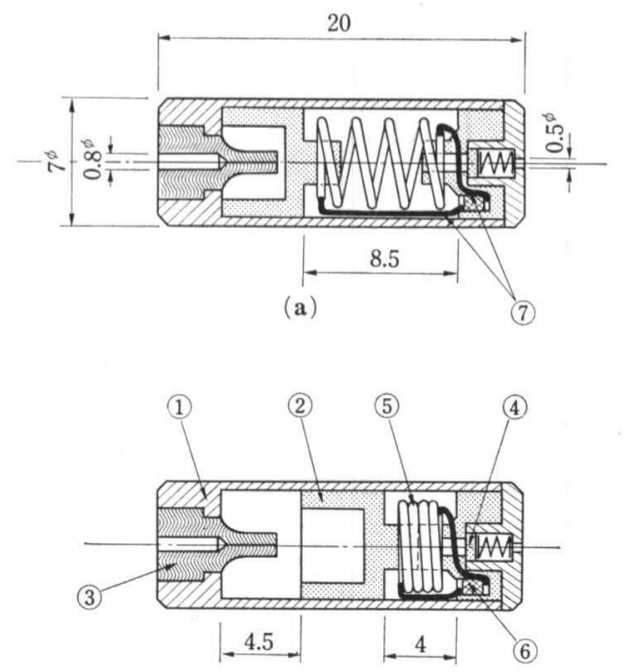

(b)

Fig. 1. The construction of the sampling capsule. (1) Outer part of the capsule, (2) Inner part of the capsule, (3) Suction valve, (4) Exhaust valve, (5) Ni-Ti coil, (6) Condenser, (7) Cupper ribbon. Unit $=\mathrm{mm}$.

SMA and a tip condenser is operated by high frequency wave energy resonated by the extrabody source; and thus by heating the coil, the shape memory becomes functional.

The construction of the capsule is shown in Fig. 1. When the capsule is to be used for the collection of the intestinal contents, a pressed coil shape of the alloy is memorized, and the stretched shape of the capsule is administered into the intestine, as shown in Fig. 1a. Heating by the high frequency wave energy, above the Austenite transformation temperature, the coil is pressed to move a piston to collect the intestinal contents.

\section{2) Temperature characterization of the $\mathrm{Ni}-\mathrm{Ti}$ coil}

The Ni-50 at. pet Ti alloy has been known to have a shape-memory character. The Af point (Austenite transformation finished temperature) was different when the ratio of the constituent metals, temperature of the furnace making the alloy, contaminated minor elements, and heat treatment were different. In order to examine the temperature char- acterization of the Ni-Ti coil, a $0.5-\mathrm{mm}$ diameter of the Ni-Ti wire, Af point to be 40 to $45^{\circ} \mathrm{C}$ after heat treatment, was coiled for 7 turns, with a resultant 4-mm diameter, and thus the coil was heat-treated at 400 to $500^{\circ} \mathrm{C}$. The coil was stretched at room temperature to $12 \mathrm{~mm}$ in length, and change in length of the coil was examined in warm water by changing temperature.

By changing the condition of heat treatment, effect on the temperature characterization was also examined.

\section{3) Resonance circuit, and determination of the frequency wavelength}

By the combination of the Ni-Ti coil and a ceramic tip condenser, a resonance circuit, as shown in Fig. 2, was constructed. Inductance $(\mathrm{L})$ of the Ni-Ti coil and capacitance (C) of the condenser will give the resonance frequency (f) of the circuit as the following function:

$$
f=\frac{1}{2 \pi \sqrt{L C}} .
$$

By irradiating high frequency wave of resonance frequency from outside of the body, the efficiency of energy absorption may be in the order of 10 to 100 -fold of the simple induction heating to the shapememory alloy. The frequency used for the resonance should not heat the human body, and should heat only the Ni-Ti coil in the body. Thus a 2- to $3-\mathrm{MHz}$ wavelength was used.

The high frequency induction heating apparatus is shown in Fig. 3.

Slight variations of $\mathrm{L}$ and $\mathrm{C}$ were shown due to the variation of the materials of the Ni-Ti alloy, shape of the coil, and capacitance of the condenser, and the resonance

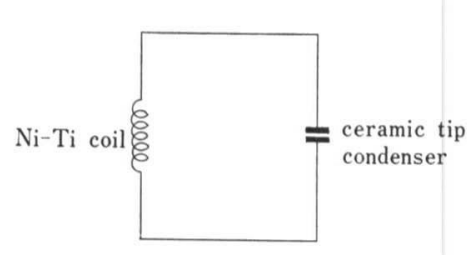

Fig. 2. Resonance circuit. 


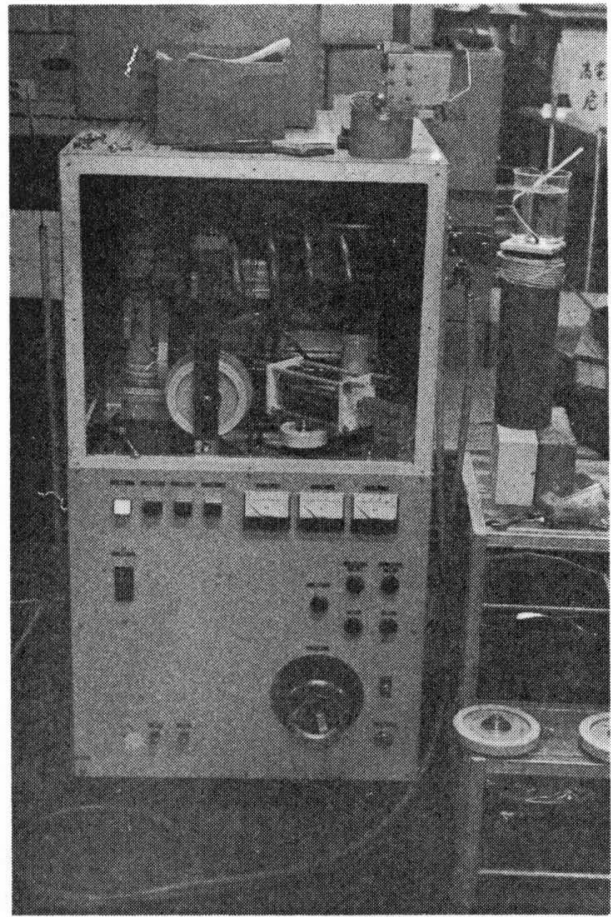

Fig. 3. High frequency induction heating apparatus.

frequency may be slightly different. Thus, the resonance frequency for the trial circuits was measured by a dip meter (DMC-230S, Mita Musen Kenkyusho, Ltd.).

\section{4) Test operations of the Ni-Ti coil}

Warm water was placed in a 3-liter beaker at $37^{\circ} \mathrm{C}$, as shown in Fig. 4, and the resonance circuit was put in a Serum Tube (Sumitomo Bakelite Co., Ltd.) which is placed in the beaker. Distance between the resonance circuit and the coil for induction heating could be altered by means of polyvinylchloride plates. A $2.7 \mathrm{MHz}$ high frequency wave was irradiated from the bottom of the beaker, and delay of the operation of $\mathrm{Ni}$-Ti coil was recorded. Angles of irradiation to the coil were alternated, and any

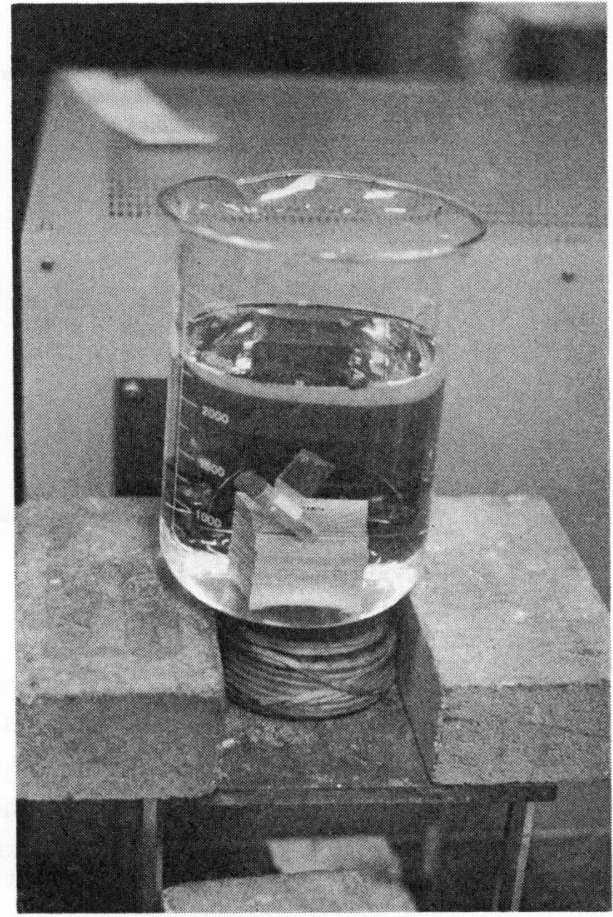

Fig. 4. Test operation of the Ni-Ti coil.

difference of the results by different angles of irradiation was examined. The $\mathrm{Ni}-\mathrm{Ti}$ alloy used was $A f=42^{\circ} \mathrm{C}$.

\section{5) Heating experiment of the agar fantom}

Muscle equivalent agar fantom for $8 \mathrm{MHz}$ (Table 1) was irradiated with 2- to $3-\mathrm{MHz}$ high frequency wave, and temperature increase was examined.

A liquid crystal thermo-sensor film, ranging from $16^{\circ} \mathrm{C}$ to $33^{\circ} \mathrm{C}$, was placed on the agar fantom of $3 \mathrm{~cm}$ in thickness, and the thermo-sensor film was enclosed with the same agar fantom. Irradiation to the agar from the bottom with 2 to $3 \mathrm{MHz}$ was performed to examine any temperature increase by color change of the liquid crystal thermosensor film (Fig. 5).

Table 1. Muscle equivalent agar fantom for $8 \mathrm{MHz}$.

\begin{tabular}{cccccccc}
\hline & \multicolumn{1}{c}{ Composition } & $(\%)$ & & $\begin{array}{c}\text { Temperature } \\
\left({ }^{\circ} \mathrm{C}\right)\end{array}$ & $\begin{array}{c}\text { Dielectric } \\
\text { constant }\end{array}$ & $\begin{array}{c}\text { Electric } \\
\text { conductivity } \\
(\mathrm{s} / \mathrm{m})\end{array}$ \\
\cline { 1 - 4 } Water & $\mathrm{NaCl}$ & $\mathrm{NaN}_{3}$ & Agar & & 23.5 & 77 & 0.6 \\
\hline 95.68 & 0.22 & 0.1 & 4 & & 23 & 77 \\
\hline
\end{tabular}




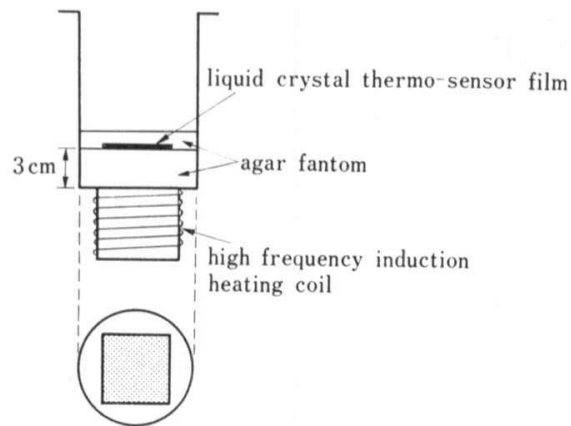

Fig. 5. Heating experiment of the agar fantom.

\section{6) Heating experiment of pork meat}

Pork meat with muscle and fatty layers was used, and the experiments as in 5) were performed. An alcohol thermometer was inserted into the superficial fatty tissue, and change in temperature with time of irradiation was observed (Fig. 6).

\section{7) Operation of the sampling capsule}

High frequency wave was irradiated $5 \mathrm{~cm}$ away from the capsule in water, as in the experiment in 4), and the time required for the sample collecting operation and amount of the sample collected were examined.

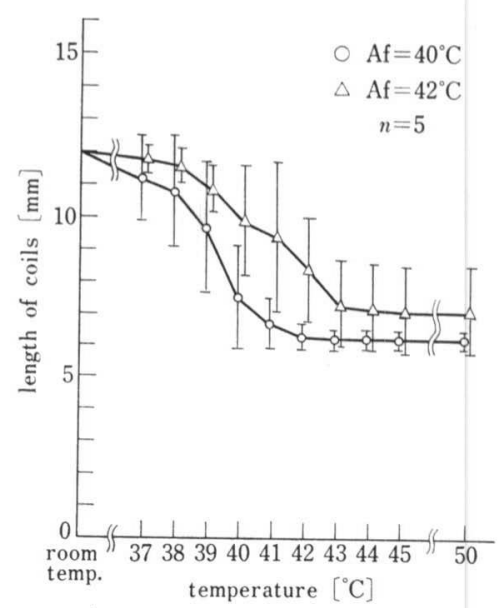

Fig. 7. Temperature characterization of the Ni-Ti coil $\left(A f=40^{\circ} \mathrm{C}\right.$ and $\left.A f=42^{\circ} \mathrm{C}\right)$.

\section{Results}

1) Temperature characteristics of the Ni-Ti coils The coils were made of the Ni-Ti SMA of $A f=40^{\circ} \mathrm{C}$ and $A f=42^{\circ} \mathrm{C}$ after heat treatment at $500^{\circ} \mathrm{C}$, and change in the length of coils was measured. The results are shown in Fig. 7. The coils with $A f=40^{\circ} \mathrm{C}$ might function at the body temperature.

Results obtained with coils of $A f=45^{\circ} \mathrm{C}$ are shown in Fig. 8. Operation was initiated at $45^{\circ} \mathrm{C}$, and the $A f$ point was more than $50^{\circ} \mathrm{C}$.

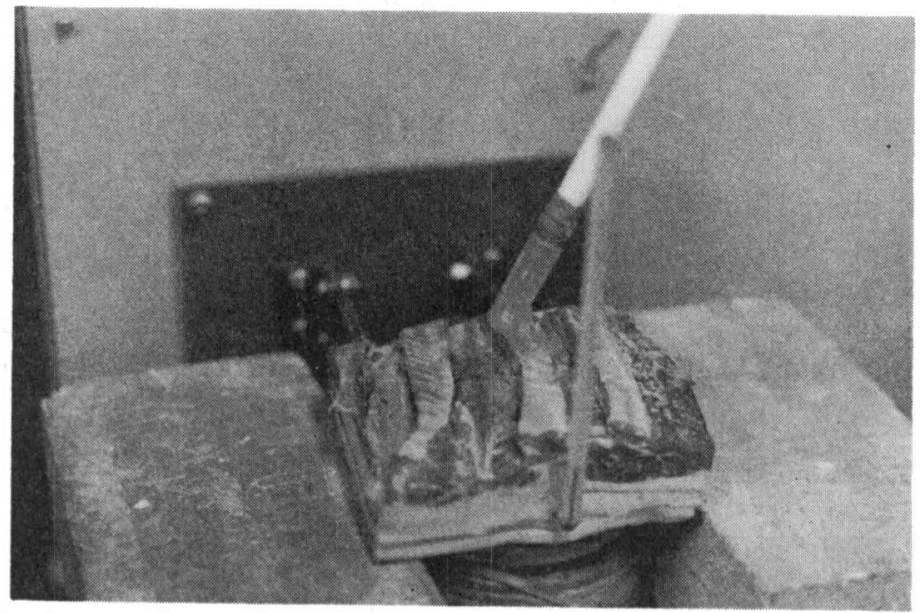

Fig. 6. Heating experiment of pork meat. (Lighting of the neon lamp shows the irradiation of the high frequency wave.) 


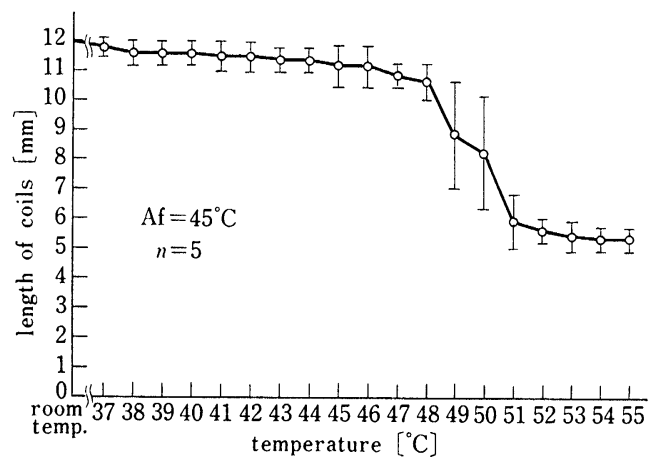

Fig. 8. Temperature characterization of the Ni-Ti coil $\left(A f=45^{\circ} \mathrm{C}\right)$.

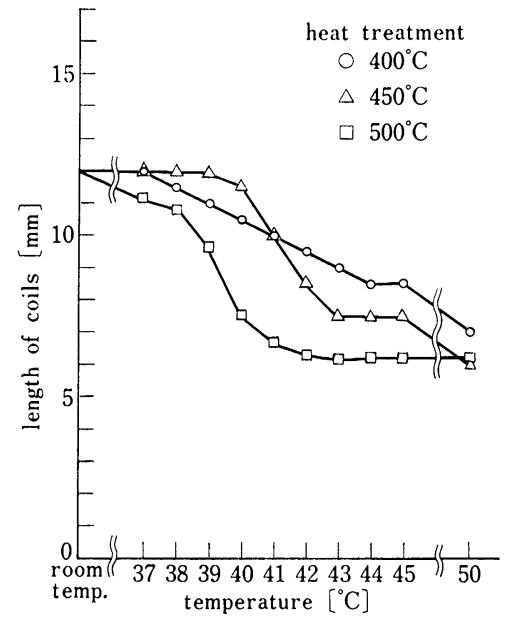

Fig. 9. The effect on the temperature characterization by changing the condition of heat treatment.

Then, the temperatures of the heat treatment were changed between $400^{\circ} \mathrm{C}$ and $500^{\circ} \mathrm{C}$, and the results are shown in Fig. 9. It may be seen that the temperature at which shape restoring was initiated differed when the heat treatment was different, and the shape-changing patterns were also different.

\section{2) Measurement of the resonance frequency}

Resonance circuits, 2 sets of A and B, as shown in Fig. 2, were constructed by the combination of the $\mathrm{Ni}-\mathrm{Ti}$ coil $(4 \mathrm{~mm}$ in diameter, 7 turns) and the ceramic tip condenser. The resonance frequencies for coil lengths of $10 \mathrm{~mm}$ and $6 \mathrm{~mm}$ were measured (Table 2).

\section{3) Operation of the $\mathrm{Ni}$ - $\mathrm{Ti}$ coils}

The distance from the top of the irradiation coil of the induction heating source to the $\mathrm{Ni}-\mathrm{Ti}$ coil in water, and the time required from the initiation of irradiation to the beginning of coil shortening and to the shrinkage finishing are shown in Table 3. At a distance of more than $6 \mathrm{~cm}$ in water, the coil did not work.

The relations between the coil operation and the angle of irradiation of high frequency wave, when the coil was placed at a $4-\mathrm{cm}$ depth, are shown in Table 4. Even when the

Table 2. Resonance frequency.

\begin{tabular}{ccc}
\hline $\begin{array}{c}\text { Length of } \\
\text { the Ni-Ti coil }\end{array}$ & $\mathrm{A}^{a}$ & $\mathrm{~B}^{a}$ \\
\hline $10 \mathrm{~mm}$ & 2.72 & 2.87 \\
$6 \mathrm{~mm}$ & 2.24 & 2.36 \\
\hline
\end{tabular}

a 2 sets of $\mathrm{A}$ and $\mathrm{B}$ were measured.

Table 3. Operation of the Ni-Ti coil (The direction of irradiation is longitudinal of the coil. $\left.\left(0^{\circ}\right)\right)$.

\begin{tabular}{ccc}
\hline $\begin{array}{c}\text { Distance } \\
(\mathrm{cm})\end{array}$ & $\begin{array}{c}\text { Delay until the } \\
\text { coil begins to } \\
\text { operate }\end{array}$ & $\begin{array}{c}\text { Time until the } \\
\text { coil has finished } \\
\text { operation }\end{array}$ \\
\hline 0 & - & in an instant \\
1 & - & $1-1.5 \mathrm{sec}$ \\
2 & - & $3.5 \mathrm{sec}$ \\
3 & - & $4.0 \mathrm{sec}$ \\
4 & - & $5.6 \mathrm{sec}$ \\
5 & $12 \mathrm{sec}$ & $17 \mathrm{sec}$ \\
6 & $15 \mathrm{sec}$ & $24-26 \mathrm{sec}$ \\
\hline
\end{tabular}

$a$ Distance from the top of the irradiation coil of the induction heating source to the $\mathrm{Ni}-\mathrm{Ti}$ coil in water.

Table 4. Difference of the operation manner according to the irradiation angle (The distance is $4 \mathrm{~cm}$.).

\begin{tabular}{ccc}
\hline $\begin{array}{c}\text { Angle of } \\
\text { irradiation } \\
\left(^{\circ}\right)\end{array}$ & $\begin{array}{c}\text { Delay until the } \\
\text { coil begins to } \\
\text { operate }\end{array}$ & $\begin{array}{c}\text { Time until the } \\
\text { coil has finished } \\
\text { operation }\end{array}$ \\
\hline 0 & - & $3.2 \mathrm{scc}$ \\
30 & - & $8.9 \mathrm{sec}$ \\
40 & $10 \mathrm{sec}$ & $44 \mathrm{sec}$ \\
60 & $18 \mathrm{sec}$ & $59 \mathrm{sec}$ \\
90 & $19 \mathrm{sec}$ & $50 \mathrm{sec}$ \\
\hline
\end{tabular}


Table 5. Heating conditions of the high frequency induction heating apparatus.

\begin{tabular}{ll}
\hline Frequency & $2.7 \mathrm{MHz}$ \\
Plate voltage & $5.2 \mathrm{kV}$ \\
Plate current & $0.52 \mathrm{~A}$ \\
Grid current & $0.40 \mathrm{~A}$ \\
\hline
\end{tabular}

Table 6. Change in temperature of the fatty layer of pork meat during the irradiation (2.7 $\mathrm{MHz})$.

\begin{tabular}{rc}
\hline $\begin{array}{c}\text { Time } \\
(\min )\end{array}$ & \multicolumn{1}{c}{$\begin{array}{c}\text { Temperature } \\
\left({ }^{\circ} \mathrm{C}\right)\end{array}$} \\
\hline 0 & 26 \\
4 & 24.5 \\
14 & 22 \\
\hline
\end{tabular}

depth of the coil was the same, the operation manner of the coil was different according to the irradiation angle of the high frequency wave energy, as shown in Table 4 . The heating conditions of the high frequency induction heating apparatus are shown in Table 5.

4) Heating experiments with agar fantom and pork meat

The liquid crystal thermo-sensor film was embedded in the agar fantom, and was irradiated for $5 \mathrm{~min}$ with $2.7-\mathrm{MHz}$ high frequency wave energy. There was no change in the color tone of the liquid crystal thermosensor film. Change in temperature of the fatty layer of pork meat when irradiated with $2.7-\mathrm{MHz}$ high frequency wave is shown in Table 6.

\section{5) Operation of the sampling capsule}

The sampling capsules were made (structure shown in Fig. 1) and then operation was observed by irradiating from a 5 -cm distance, and the operation was started about $10 \mathrm{sec}$ after beginning the irradiation, and the operation was finished in about $17 \mathrm{sec}$. The amount of water that the capsule could collect was about $100 \mu \mathrm{l}$.

\section{Discussion}

A capsule is administered into the digestive organs for the purpose of collecting samples, administering drugs, and measurements of various indices. The conventional capsule operation mechanism consists of several devices: a spring installed in the capsule is fixed with a piece of string, and the string is cut by the heat of filament operated with a battery which is controlled by an external signal, and thus the spring in the capsule functions at the specific site in the digestive organs $(3,4)$. A stopper is electrically operated by the external signal (Japan Patent Publication (Kokai) No. 77-94682). However, a battery must be installed within the capsule, and leakage of the battery contents and explosion in the body are not desirable for medical use. A minute receiver must also be installed as the starter of the capsule operation, and practical use is difficult because of higher cost price.

On the other hand, the shape-memory alloy was discovered by the Naval Ordnance Laboratory in the United States in 1963, and it was applied in various fields. As a medical capsule, it is operated by the body temperature (Japan Patent Publication (Kokai) No. 83-136332) and by heating with a battery (Japan Patent Publication (Kokai) No. 81-116445). The capsule can be heated by the Joule heat due to the high frequency wave energy (Japan Patent Publication (Kokai) No. 83-130031). However, the so-far proposed mechanisms of operation are not satisfactory for collecting an intestinal sample by the capsule at a specified site in the digestive organs.

Considering these disadvantageous points of so-far developed capsules, the operation of the capsule was much better using the shapememory alloy $\mathrm{Ni}-\mathrm{Ti}$ by heating with high frequency wave resonance energy, and the efficiency was far better than the simple induction heating. Resonance heating furnished rapid heating of the alloy, and no battery receiver nor complex electronic circuit were required for the operation of the collection capsule.

The shape-memory alloy was coiled, and a piston within the capsule was operated by means of stretching and shrinkage of the coil 
to collect the intestinal sample. The combination of the inductance of the $\mathrm{Ni}-\mathrm{Ti}$ coil and the appropriate capacitance of the tip condenser gave an efficient resonance circuit to absorb high frequency wave energy given from outside of the body.

The shape memory alloy used as the material of the coil in the capsule, for the present purpose, should not change shape by the body temperature until the capsule reaches the desired site in the digestive organs. Then, it is desirable that the Af point is slightly higher than the body temperature for rapid operation at the desired site in the digestive organs, and the difference between the As point, when the transition begins, and the Af point, when the transformation terminates, should be narrower. When the $A f$ point $40^{\circ} \mathrm{C} \mathrm{Ni-Ti}$ was used, the shape was $40 \%$ restored at $39^{\circ} \mathrm{C}$, as shown in Fig. 7 , so that the capsule with it cannot be used when the subject has fever. When $A f 45^{\circ} \mathrm{C}$ Ni-Ti was used, as shown in Fig. 8, higher than $50^{\circ} \mathrm{C}$ heating was required for complete restoration of the memorized shape, and more powerful high frequency wave energy should be used to operate the capsule more rapidly at the desired site in the digestive organs. Considering these results, we determined that the alloy $A f 42^{\circ} \mathrm{C}$ was to be used for the preparation of the coil.

High frequency wave energy irradiated from outside of the body should be less than $10 \mathrm{MHz}$. Absorption profiles of thus irradiated high frequency wave energy in the muscle and fatty layers were shown in the report of the IEEE spectrum (5). According to Sterzer et al. (5), an energy decline of about $40 \%$ at $5-\mathrm{cm}$ depth in the muscle with $13.56 \mathrm{MHz}$ was observed. High frequency wave energy of 4 to $6 \mathrm{MHz}$ is used for drying of wood materials; in the medical field 8$\mathrm{MHz}$ frequency is used for hypothermia treatment (1). An increase in the body temperature by irradiation with high frequency wave is not desirable for the present purpose. Although short irradiation to the body may not induce heating of the body, $2-$ to $3-\mathrm{MHz}$ frequency was used in our experiments for safety. In the present study, no increase in temperature was observed in the experiments with agar fantom and with pork meat.

Results showed that the resonance wavelength was altered by the length of the shapememory alloy coil and by the capacitance variation of the condenser (Table 2). Thus, the frequency should be changed according to the length of the coil for the best performance, but the shrinkage of the $\mathrm{Ni}-\mathrm{Ti}$ coil is relatively rapid, so that the frequency should be adjusted to the length of the coil after stretching when the coil is used for collecting the intestinal sample.

About $80 \%$ of the soft tissue of human body consists of water. High frequency wave can be transmitted easily in air but it will decline considerably in water. Although attenuation patterns of the transmission of high frequency wave in water and in human body may be slightly different, it was thought that the capsule could be operated in any site of the intestine, if the high frequency wave energy can reach a depth of 10 to $15 \mathrm{~cm}$ in water. But the results of the present experiment showed that increasingly more time was required for heating as the distance from the irradiation coil of the induction heating source to the capsule in water became greater. And the heating was impossible when the distance exceeded $6 \mathrm{~cm}$ (Table 3). Time required for the operation of the capsule was influenced by the angle of irradiation (Table 4). High frequency magnetic field is absorbed along with the longitudinal direction of the coil, so that declined irradiation angle gives only the vector component energy to the longitudinal direction. If the output power of the high frequency wave energy is increased, it might be effective for heating the coil in the body, but such high-power apparatus will be more expensive for practical use.

Acknowledgements. The present paper was prepared by the Capsule Research Group, based on the research sponsored by the Life Technology Research Foundation. We express sincere thanks to Prof. Funakubo, Faculty of Engineering, The University of Tokyo. 


\section{References}

(1) Hiraoka, M., S. Jo, Y. Dodo, K. Ono, M. Takahashi, H. Nishida, and M. Abe, 1984. Clinical results of RF hyperthermia combined with radiation in the treatment of radioresistant cancers. Cancer 52: 2898-2904.

(2) Hirtzmann, M. 1965. Erfahrungen mit der automatischen Darmkapsel, einen neuen Gerät zur bakteriologischen Untersuchung höherer Darmabschnitte. Ernährung 10: 424-428.
(3) Ishiwara, T. 1977. Recent development on capsule for digestive tracts. J. Jpn. Soc. Precision Eng. 43: 626-628 (in Japanese).

(4) Ishiwara, T. 1977. Study on development of capsule for liquid sampling in the digestive tract. Proceedings of the 16th Conference. Jpn. J. Med. Elect. Biol. Engin. 15 (Suppl.): 264-265 (in Japanese).

(5) Sterzer, F., R.W. Paglione, J. Mendecki, E. Friedenthal, and C. Botstein, 1980. RF therapy for malignancy, IEEE Spectrum, 17(12): 32-37. 